\title{
Stress among Nursing and Midwifery Students Offering a Top-Up Module in the University of Health and Allied Health Sciences, Ho
}

\author{
Francis Wadga-Mieza Yankey ${ }^{*}$, Dominic Agyei Dankwah ${ }^{2}$, \\ Lily Adu-Aboagye ${ }^{3}$, Anthony Asempah4, Emmanuel Barima Agyemang Prempeh5, \\ Samuel Forkuo5, Gifty Aba Doe 6 \\ ${ }^{1}$ Student Affairs Unit, University of Health and Allied Sciences, Ho, Ghana \\ ${ }^{2}$ University Library, University of Health and Allied Sciences, Ho, Ghana \\ ${ }^{3}$ Office of the Registrar, University of Health and Allied Sciences, Ho, Ghana \\ ${ }^{4}$ Public Affairs Unit, University of Health and Allied Sciences, Ho, Ghana \\ ${ }^{5}$ Academic Affairs Unit, University of Health and Allied Sciences, Ho, Ghana \\ ${ }^{6}$ School of Basic and Biomedical Sciences, University of Health and Allied Sciences, Ho, Ghana \\ Email: ‘fyankey@uhas.edu.gh, dadankwah@uhas.edu.gh, laboagye@uhas.edu.gh, asempah@uhas.edu.gh, \\ eprempeh@uhas.edu.gh,sforkuo@uhas.edu.gh,gadoe@uhas.edu.gh
}

How to cite this paper: Yankey, F.W.-M., Dankwah, D.A., Adu-Aboagye, L., Asempah, A., Prempeh, E.B.A., Forkuo, S. and Doe, G.A. (2017) Stress among Nursing and Midwifery Students Offering a Top-Up Module in the University of Health and Allied Health Sciences, Ho. Open Access Library Journal, 4: e3318.

http://dx.doi.org/10.4236/oalib.1103318

Received: December 20, 2016

Accepted: January 9, 2017

Published: January 12, 2017

Copyright $\odot 2017$ by authors and Open Access Library Inc.

This work is licensed under the Creative Commons Attribution International License (CC BY 4.0).

http://creativecommons.org/licenses/by/4.0/

\begin{abstract}
Previous studies have posited that students studying in medical-related fields are particularly susceptible to high levels of academic stress with implication for both psychological and physical health. This study set in the environment of a newly established public university in Ghana, seeks to evaluate the levels and component stress among students offering nursing and midwifery in the top-up module in the University of Health and Allied Science, Ho. In descriptive study using a modified version of the pre-validated College Undergraduate Stress Scale, 315 second and third year Midwifery 82 (26.03\%), Nursing 155 (49.21\%) and Public Health Nursing 78 (24.76\%) students obtaining bachelors degree in top-up module were surveyed for this study. Among the total study population, 109 (34.60\%) experienced high stress level, 106 (33.65\%) experienced moderate stress level and 100 (31.75\%) experienced less stress level. Stress levels were higher among the female participants. Participants with children under 13 years and female participants with breastfeeding babies showed higher levels of stress. A majority of students in the sandwich top-up bachelor degree programme experience moderate to high stress mostly due to curriculum overload. Therefore, innovative means should be sought to lessen the level of stress among this category of students. For example, pre-recorded video lectures could be incorporated into the module to lessen the overload in school work.
\end{abstract}




\section{Subject Areas}

Education

\section{Keywords}

Stress, Academic Stress, Nursing Education, College Undergraduate Stress Scale, Component Stressors

\section{Introduction}

Stress has been identified as a 20th century disease and has been viewed as a complex and dynamic transaction between individuals and their environment [1]. The modern stress theory is structured in the evaluation of the meaningfulness of an event(s) to the individuals' psychological or physical well-being and the internal compensatory mechanisms adapted to cope for the perturbations induced by the external event(s) [2]. An individual's response to an event thus depends on whether it is appraised as a challenge which would lead to a positive outcome or as a threat which could lead to distress, anxiety, depression, social dysfunction, ill health and even suicidal tendencies [3] [4].

Stress has become an important topic in academic circle and students have always been perceived as stressed individuals due to the amount of academic workload they bear [5] [6]. Academic stress is conceptualized as interactions between student's environment stressors, cognitive appraisal and coping with physiological and psychological response to stress and stressors related to academics [7] [8]. In the event of a harsh and extended stress, recorded impact includes reduced or compromised academic performance, hindrance to involvement in campus life (Social withdrawal), dropout, increase probability of substance abuse and other potentially destructive behaviours [9] [10].

Previous studies have posited that students studying in medical-related fields are particularly liable to experience high levels of academic stress [4] [6] [11] [12]. According to Jacob and Einstein (2016), attributable causes of higher manifestation of academic stress in healthcare students include the expansion of the knowledge base of such profession and the acquisition of clinical skills which demand a significant amount of both theoretical and education practice hours [12].

Despite the growing interest in academic related stress and advancement in strategies for coping mechanisms and stress management among students in other jurisdictions, there is limited data on stress and its related issues among university undergraduates in general and nursing and midwifery students in particular in the Ghanaian literature. This study, set in the environment of a newly established public university in Ghana, seeks to evaluate the levels and component stress among students offering nursing and midwifery in the top-up module in the University of Health and Allied Science, Ho. 


\section{Method}

\subsection{Participants}

The study population comprised of Sandwich students in the School of Nursing and Midwifery at the University of Health and Allied Sciences. These students are professionals practicing on the field with the Ministry of Health, Ghana certificates who have enrolled in a three-year part-time top-up programme to obtain bachelor degree in the University.

The total study population was estimated at 374 comprising 297 in the second year and 77 in the third year. The study was descriptive with a self-administered survey instrument administered at one time point. The sampling included all students who were present in their class at the time of the administration of the questionnaire. A total of 315 of the 374 administered questionnaires were completed by participants and returned, making a total response rate of $84.22 \%$. Among these participants, the response rate was $84.85 \%$ among those in the second year and $81.82 \%$ among those in their third year.

\subsection{Tools}

The tool used for this study comprised of an inventory that captured the demographic data of participants which included age, gender, marital status, number of children under 13 years and the number of breastfeeding babies. The stress inventory used was a modified version of the pre-validated College Undergraduate Stress Scale (CUSS) [13]. The CUSS is 53 item stress scale that measures the overall stress levels as well as four component stress domains namely Academic stress, Interpersonal stress, Intrapersonal stress and Environmental stress. The CUSS measures the levels of stress with a pre-assigned weighting on each item denoting the degree of stress. The overall cumulative stress score/weight in this modified version was 3656 . Among the component stress, academic stress with 27 items had a maximum score of 1852; interpersonal stress (11 items had a maximum score of 795); intrapersonal (6 items had a maximum score of 466); and environmental stress ( 9 items had a maximum score of 543).

\subsection{Procedure}

Permission for the conduct of this research was granted by the University's Student Affairs Unit in a letter (UHAS/SA/AD/0036). Prior to responding to the self-administered questionnaires, an interactive orientation briefing was organized with students regarding the purpose of the study and the need to answer all the questions frankly. The study was anonymous and non-linked, participation was voluntary and all participants consented to the study. Confidentiality of participant's information was assured.

\subsection{Data Analysis}

The sum of weights/scores for each section and the total weight/score of stress were transformed to a percentage scale from 0 to 100 with higher weight/scores 
indicating greater severity of stress by applying the generic linear transformation formula [14].

$$
\frac{(\text { Gross attained domain stress wieght })}{(\text { Maximum attainable domain stress wieght })} \times 100
$$

Since every item in the CUSS is weighted, the attained domain stress weight is the cumulative sum of the assigned weights of all affirmed item in the domain, the maximum attainable domain stress weight is the cumulative sum of assigned weights of all the terms that makeup that domain.

For the purpose of this study a tertile rank of stress was adopted where a participant with a total percentage weight/score below $33.33 \%$ was categorized as experiencing low level of stress; a total percentage weight/score of $33.33 \%$ to $66.67 \%$ was categorized as experiencing moderate level of stress; and a total percentage weight/score above $66.67 \%$ was categorized as experiencing high level of stress.

Categorical outcomes were expressed as frequency and percentage and continuous variables as mean \pm standard deviation using Grap hPad Prism version 6.00 statistical package (Graph Pad software, San Diego, California USA, www.graphpad.com) for windows in analysis.

\section{Results}

All the presentation made in the results section is from data obtained in this study. In this study, three hundred and fifteens and which students with an average age of $30.83 \pm 4.06$ years were recruited. The study participants included $252(80.00 \%)$ second year and $63(20.00 \%)$ third year students.

The study was made up of a female population of one hundred and ninetyfour $194(61.60 \%)$ and a male population of one hundred and twenty-one 121 (38.40\%). Majority of the study participants were married 174 (55.24\%). This study included participants pursuing Bachelor of Nursing 155 (49.21\%), Bachelor of Midwifery 82 (26.03\%) and Bachelor of Public Health Nursing 78 (24.76\%). Among the female population, 92 (47.42\%) reported to have one or more children under the age of 13 years and in addition, 28 (14.43\%) were breastfeeding mothers (see Table 1).

Among the total study population, 109 (34.60\%) experienced high stress level, 106 (33.65\%) experienced moderate stress level and 100 (31.75\%) experienced less stress level. Academic stress 111 (35.24\%) and intrapersonal stress 111 (35.24\%) were the highest component stress experienced by students. The least component stress experienced was interpersonal stress 106 (33.65\%) (see Table 2).

In general, the male students experienced higher percentage stress 44 (36.36\%) than their female counterpart 65 (33.51\%). The male students experienced more interpersonal 60 (30.93\%) and environmental 56 (28.87) component stress than the female students whiles the female students experienced more academic 71 (36.60\%) and intrapersonal 72 (37.11) component stress. 
Table 1. Socio-demographic characteristics of study population.

\begin{tabular}{|c|c|c|c|}
\hline Parameter & Total & Female $(n=194)$ & Male $(n=121)$ \\
\hline Total respondents & $315(100)$ & $194(61.60)$ & $121(38.40)$ \\
\hline Age & $30.83 \pm 4.06$ & $31.23 \pm 4.8$ & $30.25 \pm 2.49$ \\
\hline \multicolumn{4}{|l|}{ Marital status } \\
\hline Single & $141(44.76)$ & $82(42.27)$ & $59(48.76)$ \\
\hline Married & $174(55.24)$ & $112(57.73)$ & $62(51.24)$ \\
\hline \multicolumn{4}{|l|}{ Programme of study } \\
\hline Bachelor of midwifery & $82(26.03)$ & $82(42.27)$ & $0(0.00)$ \\
\hline Bachelor of nursing & $155(49.21)$ & $63(32.47)$ & $92(76.03)$ \\
\hline Bachelor of public health nursing & $78(24.76)$ & $49(25.26)$ & $29(23.97)$ \\
\hline \multicolumn{4}{|l|}{ Level of study } \\
\hline Level 200 & $252(80.00)$ & $144(74.23)$ & $108(89.26)$ \\
\hline Level 300 & $63(20.00)$ & $50(25.77)$ & $13(10.74)$ \\
\hline \multicolumn{4}{|l|}{ Number of children under 13 years } \\
\hline None & $177(56.19)$ & $102(52.58)$ & $75(61.98)$ \\
\hline One & $71(22.54)$ & $44(22.68)$ & $27(22.32)$ \\
\hline Two & $45(14.29)$ & $36(18.55)$ & $9(7.44)$ \\
\hline More than two & $22(6.98)$ & $12(6.19)$ & $10(8.26)$ \\
\hline \multicolumn{4}{|l|}{ Number of breastfeeding children } \\
\hline None & $267(84.76)$ & $166(85.57)$ & $101(83.47)$ \\
\hline One or more & $46(14.64)$ & $28(14.43)$ & $20(15.24)$ \\
\hline
\end{tabular}

Data are presented as figure with percentage in parenthesis, mean \pm standard deviation.

Table 2. Stress level of study population.

\begin{tabular}{cccc}
\hline Parameter & Less stressed & Moderately stressed & Highly stressed \\
\hline Overall stress level & $100(31.75)$ & $106(33.65)$ & $109(34.60)$ \\
Academic stress level & $100(31.75)$ & $104(33.01)$ & $111(35.24)$ \\
Interpersonal stress level & $103(32.70)$ & $106(33.65)$ & $106(33.65)$ \\
Intrapersonal stress level & $80(25.40)$ & $124(39.37)$ & $111(35.24)$ \\
Environmental stress level & $102(32.38)$ & $104(33.01)$ & $109(34.60)$ \\
\hline
\end{tabular}

Data are presented as figure and percentage in parenthesis.

This study also revealed that students who were single experienced higher percentage of stress than students who were married. Similarly, the third-year students also experienced higher percentage of stress than the second-year students.

Students pursuing Bachelor of Nursing were the most stressful group of students. The exception though was found in the academic component stress where the Bachelor of Public Health Nursing recorded the highest 29 (37.18\%) (Table 3). 
Table 3. Highly stressed levels among study population stratified into gender, marital status, level of study and programme of study.

\begin{tabular}{|c|c|c|c|}
\hline Gender & Female & Male & \\
\hline Overall stress & $65(33.51)$ & $44(36.36)$ & \\
\hline Academic stress & $71(36.60)$ & $40(33.06)$ & \\
\hline Interpersonal stress & $60(30.93)$ & $46(38.02)$ & \\
\hline Intrapersonal stress & $72(37.11)$ & $39(32.23)$ & \\
\hline Environmental stress & $56(28.87)$ & $53(43.80)$ & \\
\hline Marital status & Single & Married & \\
\hline Overall stress & $52(36.88)$ & $57(32.76)$ & \\
\hline Academic stress & $51(36.17)$ & $60(34.48)$ & \\
\hline Interpersonal stress & $51(36.17)$ & $55(31.61)$ & \\
\hline Intrapersonal stress & $50(35.46)$ & $61(35.06)$ & \\
\hline Environmental stress & $49(34.75)$ & $60(34.48)$ & \\
\hline Year of study & Second & Third & \\
\hline Overall stress & $82(32.54)$ & $27(42.86)$ & \\
\hline Academic stress & $83(32.94)$ & $28(44.44)$ & \\
\hline Interpersonal stress & $82(32.54)$ & $24(38.10)$ & \\
\hline Intrapersonal stress & $86(34.13)$ & $25(39.68)$ & \\
\hline Environmental stress & $87(34.52)$ & $22(34.92)$ & \\
\hline Programme of study & B. Mid & B. Nurs & B. PHN \\
\hline Overall stress & $22(26.83)$ & $60(38.71)$ & $27(34.62)$ \\
\hline Academic stress & $25(30.49)$ & $57(36.77)$ & $29(37.18)$ \\
\hline Interpersonal stress & $28(34.15)$ & $59(38.06)$ & $19(24.36)$ \\
\hline Intrapersonal stress & $28(34.15)$ & $58(37.42)$ & $25(32.05)$ \\
\hline Environmental stress & $21(25.61)$ & $61(39.35)$ & $27(34.62)$ \\
\hline
\end{tabular}

Data are presented as figure and percentages in parenthesis. B. Mid, B. Nurs, and B. PHN means bachelor of midwifery, bachelor of nursing and bachelor of public health nursing respectively.

As shown in Table 4, among the top 10 stressors, the top 3 stressors were; sense of overload in school work, late closing of classes and financial difficulties. Out of these top 3 stressors, the first two belongs to the academic component stress and the third belongs to the intrapersonal component stress. Academic component stress made up $70.00 \%$ of the top 10 stressors. All the top 10 stressors recorded a response percentage rate of more than $69.00 \%$ of total respondents.

As shown in Figure 1 and Figure 2, the lead component stressor in academic stress domain was sense of overload in school work, interpersonal was death of a close friend, intrapersonal was financial difficulties and environmental was difficulties in getting accommodation. Higher stressors values were found in the academic component stress whiles the interpersonal component stress recorded the least. 


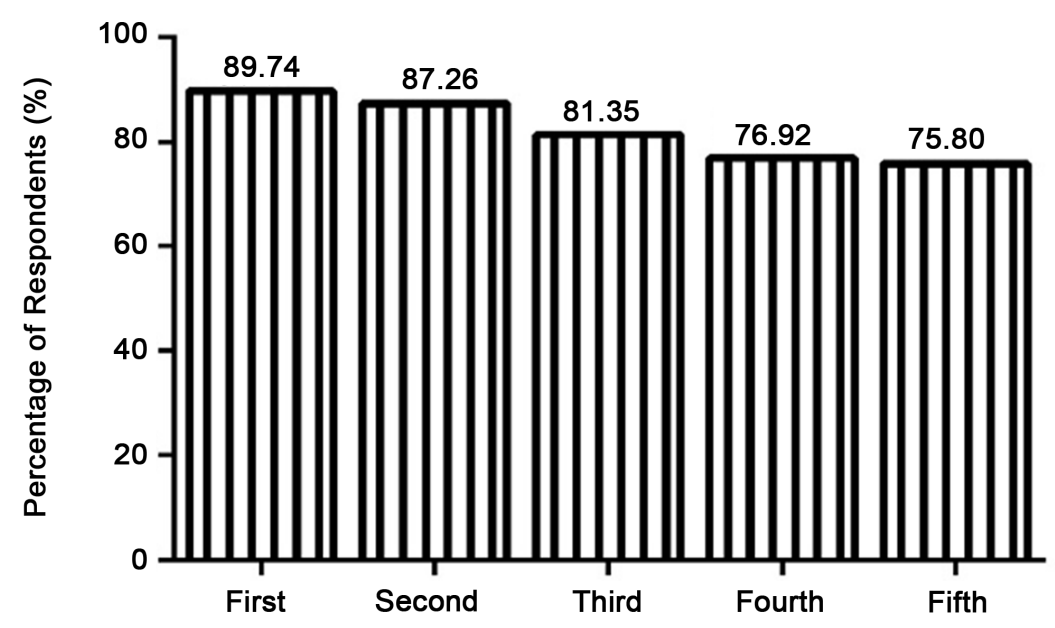

Academic Stressors

1 st $=$ Sense of overload in school work

2nd = Late closing of classes

3rd $=$ Thought of examination in the finals week

4th $=$ Final Grades

5th = Concern about my grades

(a)

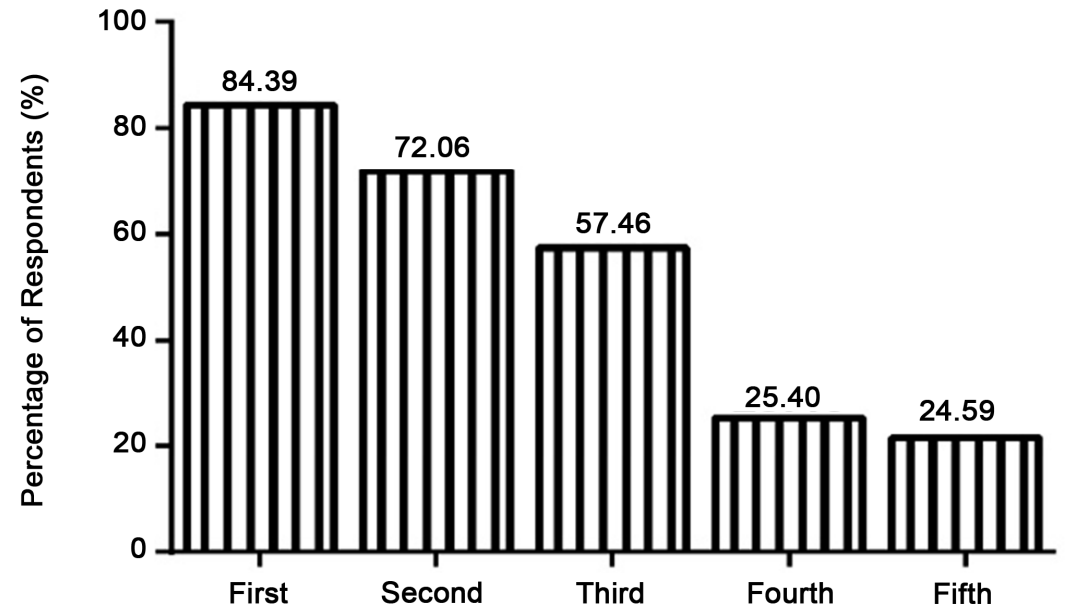

Intrapersonal Stressors

$$
\begin{aligned}
& 1 \text { st }=\text { Financial difficulties } \\
& \text { 2nd = Lack of sleep } \\
& \text { 3rd }=\text { Getting sick } \\
& \text { 4th = Concerns about being pregnant } \\
& \text { 5th }=\text { Contracting a sexually transmitted disease }
\end{aligned}
$$

(b)

Figure 1. Top component stressors in the academic and intrapersonal stress domains. 


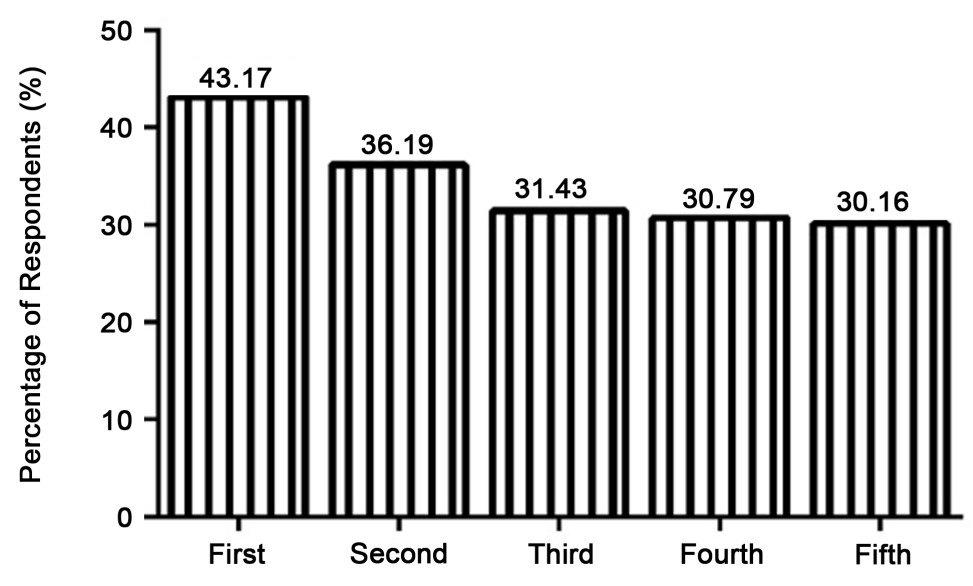

Interpersonal Stressors

$1 \mathrm{st}=$ Death of a close family member

2nd = Making new friends

3rd = Serious illness in a close friend or family member

4th $=$ Confrontations with Lecturer(s)

5 th $=$ Depression or crisis in your best friend

(a)

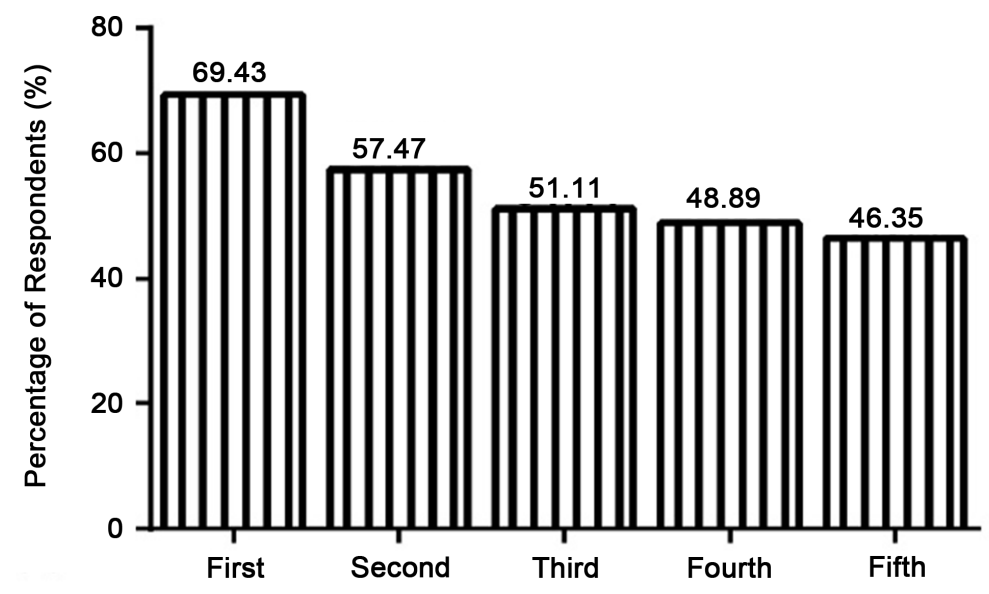

Environmental Stressors

$$
\begin{aligned}
& \text { 1st }=\text { Difficulties in accommodation } \\
& \text { 2nd }=\text { Change in housing situation } \\
& \text { 3rd }=\text { Commuting to campus } \\
& \text { 4th }=\text { Poor classroom Lighting } \\
& \text { 5th }=\text { Being away from home }
\end{aligned}
$$

(b)

Figure 2. Top component stressors in the interpersonal and environmental stress domains. 
Table 4. Top 10 itemize stressors among the study participants.

\begin{tabular}{cccc}
\hline Stressors & Category of stressor & Frequency & Percentage \\
\hline Sense of overload in school work & Academic & 280 & 89.74 \\
Late closing of classes & Academic & 274 & 87.26 \\
Financial difficulties & Intrapersonal & 265 & 84.39 \\
Thought of examination in the finals week & Academic & 253 & 81.35 \\
Final grades & Academic & 240 & 76.92 \\
Concern about my grades & Academic & 238 & 75.80 \\
Registration & Academic & 232 & 74.12 \\
Lack of sleep & Intrapersonal & 227 & 72.06 \\
Too early classes & Academic & 219 & 69.97 \\
Difficulties in getting accommodation & Environmental & 218 & 69.43 \\
\hline
\end{tabular}

Data are presented as figure and percentages in parenthesis.

The prevalence of the top five academic, interpersonal, intrapersonal and environmental component stressors ranges from (75.80\% to $89.74 \%)$, (30.16\% to $43.17 \%),(24.59 \%$ to $84.39 \%)$ and $(46.35 \%$ to $69.43 \%)$ respectively.

In general, among the female participants who have children under 13 years, stress levels increase with increasing number of children under the age of 13 years and breastfeeding mothers recorded a higher stress level than mothers who were not breastfeeding (see Figure 3).

\section{Discussion}

High levels of stress among students could lead to both psychological and physical health-related problems [15], [16]. In the current study, the prevalence of stress among the respondents was $34.75 \%$ high stress and $33.65 \%$ moderate level of stress. Varying prevalence of high level of stress among nursing and midwifery students have been reported in other jurisdictions. Among the studies reporting similar levels of stress among students, Kevin et al. (2015) in Piparia India, reported that $30 \%$ of nursing students in their first years of their bachelors degree programme experienced severe levels of stress [17]. Samson-Akpan, John, Edet, and Ella (2015) reported $33.80 \%$ in University of Calabar, Nigeria and Nancy (2011) reported 33.00\% in Punjab in India [18]. Higher levels of stress has also been reported by Amr et al. (2011), 40.2\% in Mansoura University, Egypt [19], Shiferaw et al. (2015), 47.7\% in Jimma University Ethiopia [20] and Khater, Akhu-Zaheya, and Shaban (2014), 47.82\% in Jordan [21].

However, according to the trans-cultural model, it is difficult to compare stress levels between different population in different jurisdictions because the individual's interpretation of a situation to be stressful or not, could be explained by individual's perceptual and cognitive processes [21]. The varying prevalence of high stress level among nursing and midwifery students may be attributed to the differences in socio demographic characteristics, campus environment, teaching curriculum and type of coping strategies used [22]. 


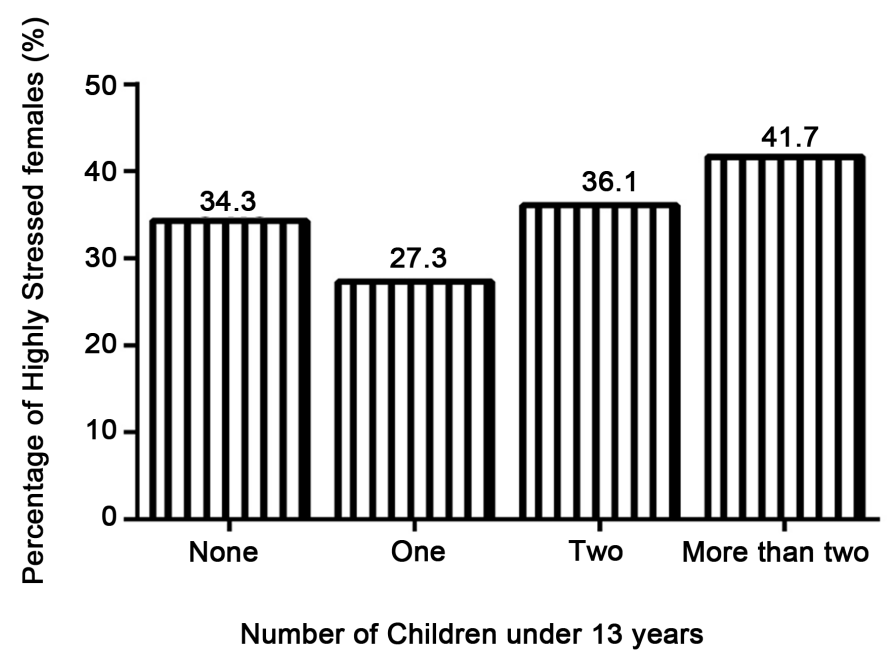

(a)

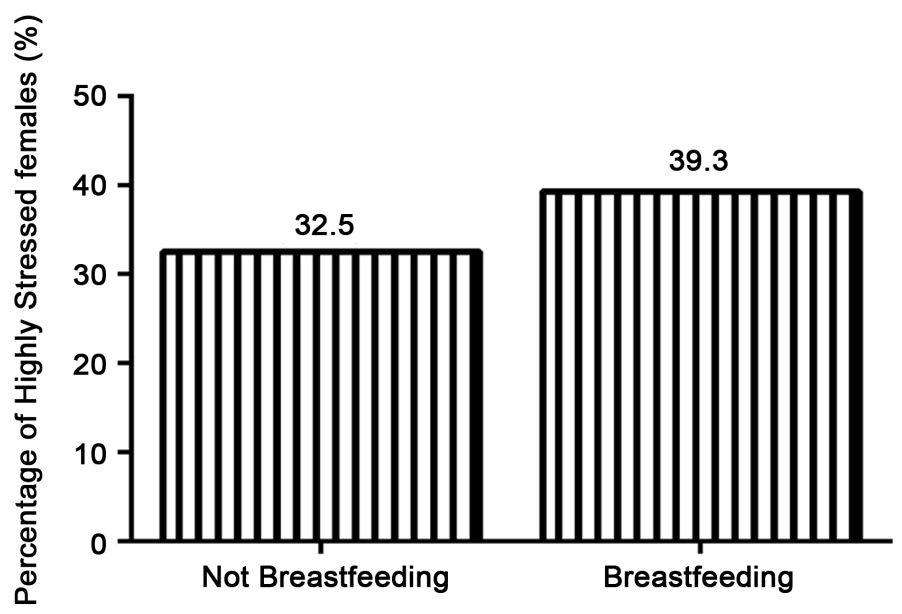

(b)

Figure 3. Proportion of highly stressed females with children under 13 years and breastfeeding babies.

In an attempt to explain the reasons for the high stress levels among nursing students in Egypt, Amr, El-Gilany, El-Moafee, Salama and Jimenez (2011) posited that increasing number of students coupled with the passive learning environments which foster memorization by students at the expense of synthesizing, problem solving and creative thinking abilities that impair the clinical skill training may be the malefactor [19]. This assertion could also be said to account for the levels of stress among students in the current study.

Generally, male students relatively experienced more stress (36.36\%) than their female counterparts (33.51\%). However, for academic and intrapersonal component stress the females experienced more stress $(36.60 \%$ and $37.11 \%$ respectively) than the males (33.06\% and $32.23 \%$ respectively). Kumar and Bhukar (2013) reported higher levels of stress in female college students than males [23]. Women face a number of chronic burdens in everyday life because of their social status and roles relative to men and this strain could account for the higher levels of stress [24]. 
This study revealed that female participants who had children under 13 years or who were breastfeeding had higher stress levels than other participants (females not breastfeeding or without children under 13 years). This findings could be attributed to the multiple role and increased work load of such participants (child caring and studying at the same time) as corroborated in the study conducted b [25].

In the present study, the third-year students experienced higher levels of stress than their second-year colleagues. This finding supports that of Elias, Ping and Abdullah (2011) who reported a mean academic stress score among second-year undergraduate students compared to their first-year counterparts [26]. Health science education gets difficult as students progress to higher levels of study [27]. As students move from one level of study to another, there is an increase in academic demands coupled with environmental and personal burden and hence could account for higher percentage stress [26].

Although the difference in the expression of the individual component stress was not profound, the top 10 stressor items was found to make $70 \%$ of the Academic stress domain (Table 3 ).

This is in agreement with the findings by [15] [20] [21]. In concordance with these research findings, the sense of overload in school work was the leading itemized stressor. This could be explained by the nature of the sandwich programme which leads to crushed courses within a short period of time.

\section{Conclusion}

A majority of students in the sandwich top-up bachelor degree programme experience moderate to high stress mostly due to curriculum overload. Therefore, innovative means should be pursued to lessen the level of stress among this category of students. For example, pre-recorded video lectures could be incorporated into the module to lessen the overload in school work.

\section{Acknowledgements}

We want to thank the management of the University of Health and Allied Sciences for allowing us the permission to carry out this study in their facility. Our sincere gratitude goes to Mr. Romeo Asumbasiya Aduko, Miss Judith Emefa Wotortsi and Miss Ethel Onipede Foluke for their various contributions to the success of this project.

\section{Competing Interests}

Authors have declared that no competing interests exist.

\section{Authors Contributions}

This work was carried out with collaboration between all authors. Authors FWMY, DAD, LAA, AA, EBAP, SF and GAD conceptualized and designed the study. Authors FWMY, DAD and LAA recruited participants and generated the data. Authors FWMY, DAD, LAA, AA, EBAP, SF and GAD analysed the data 
and drafted the manuscript. All Authors reviewed the manuscript for intellectual content and each author approved the final manuscript.

\section{References}

[1] Evans, W. and Kelly, B. (2004) Pre-Registration Diploma Students Nurse Stress and Coping Measures. Nurse Education Today, 24, 473-482. https://doi.org/10.1016/j.nedt.2004.05.004

[2] Thawabieh, A.M. and Qaisy, L.M. (2012) Assessing Stress among University Students. American International Journal of Contemporary Research, 2, 110-116.

[3] Nandamuri, P.P. and Gowthami, C. (2011) Sources of Academic Stress: A Study on Management Students. Journal of Management Sciences, 1, 31-42.

[4] Punita, P., Saranya, K. and Kumar, S.S. (2016) Gender Difference in Heart Rate Variability in Medical Students and Association with the Level of Stress. National Journal of Physiology, Pharmacy and Pharmacology, 6, 431-437.

[5] Joseph, E. (2009) An Assessment of Academic Stress among Undergraduate Students: The Case of University of Botswana. Educational Research and Reviews, 4, 63.

[6] Rahim, M., Saat, N., Aishah, H.S., Arshad, S., Aziz, N., Zakaria, N., Kaur, K., Kamaruddin, M. and Suhaimi, N. (2016) Relationship between Academic Workload and Stress Level among Biomedical Science Students in Kuala Lumpur. Journal of Applied Sciences, 16, 108-112. https://doi.org/10.3923/jas.2016.108.112

[7] Kaur, M. and Kaur, G. (2016) Academic Stress in Relation to Emotional Stability of Adolescent Students. International Journal of Social Sciences and Management, 4, $35-41$.

[8] Sharma, B., Kumar, A. and Sarin, J. (2016) Academic Stress, Anxiety, Remedial Measures Adopted and Its Satisfaction among Medical Students: A Systematic Review. International Journal of Health Sciences and Research, 6, 368-376.

[9] Khan, M.J., Altaf, S. and Kausar, H. (2013) Effect of Perceived Academic Stress on Students' Performance. FWU Journal of Social Sciences, 7, 146.

[10] Crego, A., Carrillo-Diaz, M., Armfield, J.M. and Romero, M. (2016) Stress and Academic Performance in Dental Students: The Role of Coping Strategies and Examination-Related Self-Efficacy. Journal of Dental Education, 80, 165-172.

[11] Hirsch, C.D., Barlem, E.L.D., Tomaschewski-Barlem, J.G., Lunardi, V.L. and Oliveira, A.C.C. (2015) Predictors of Stress and Coping Strategies Adopted by Nursing Students. Acta Paulista de Enfermagem, 28, 224-229. https://doi.org/10.1590/1982-0194201500038

[12] Jacob, T. and Einstein, O. (2016) Stress among Bachelor Physical Therapy Students in Israel during Clinical Practice and Its Association with Academic Achievements: Results of a Longitudinal Study. Internet Journal of Allied Health Sciences and Practice, 14, 9.

[13] Renner, M.J. and Mackin, R.S. (1998) A Life Stress Instrument for Classroom Use. Teaching of Psychology, 25, 46-48. https://doi.org/10.1207/s15328023top2501_15

[14] De Queiroz, F.A., Pace, A.E. and dos Santos, C.B. (2009) Cross-Cultural Adaptation and Validation of the Instrument Diabetes-39 (D-39): Brazilian Version for Type 2 Diabetes Mellitus Patients-Stage 11. Revista Latino-Americana de Enfermagem, 17, 708-715. https://doi.org/10.1590/S0104-11692009000500018

[15] Seyedfatemi, N., Tafreshi, M. and Hagani, H. (2007) Experienced Stressors and Coping Strategies among Iranian Nursing Students. BMC Nursing, 6, 11. 
https://doi.org/10.1186/1472-6955-6-11

[16] Singh, N. and Kohli, C. (2015) Stress Reaction and Coping Strategies among Nursing Students in Delhi. Asian Journal of Nursing Education and Research, 5, 274278. https://doi.org/10.5958/2349-2996.2015.00054.3

[17] Kevin, C., Ravindra, H.N., Priyanka, R.W., Ulpi, V., Dhenuka, W., Hemangini, T., Freni, S. and Utsav, P. (2015) Assess the Level of Stress and Coping Strategies of Student Nurses during Their Initial Clinical Practice, with a View to Develop Self-Instruction Module. Journal of Medical Sciences, 4, 112-115.

[18] Samson-Akpan, P., John, M.E., Edet, O.B. and Ella, R.E. (2015) Stress and Coping Strategies among Undergraduate Nursing Students in University of Calabar, Nigeria.

[19] Amr, A., El-Gilany, A.-H., El-Moafee, H., Salama, L. and Jimenez, C. (2011) Stress among Mansoura (Egypt) Baccalaureate Nursing Students. Pan African Medical Journal, 8, 26. https://doi.org/10.4314/pamj.v8i1.71083

[20] Shiferaw, N.H., Anand, S. and Nemera, N.G. (2015) Stress and Coping Strategies among Generic BSc Nursing Students of Jimma University, South West Ethiopia. International Journal of Recent Advances in Multidisciplinary Research, 2, 05110517.

[21] Khater, W., Akhu-Zaheya, L. and Shaban, I. (2014) Sources of Stress and Coping Behaviours in Clinical Practice among Baccalaureate Nursing Students. International Journal of Humanities and Social Science, 4, 194-202.

[22] Nancy, R. (2011) Stress and Coping Strategies among Nursing Students. Nursing and Midwifery Research Journal, 7, 141-151.

[23] Kumar, S. and Bhukar, J. (2013) Stress Level and Coping Strategies of College Students. Journal of Physical Education and Sport Management, 4, 5-11.

[24] Nolen-Hoeksema, S. (2001) Gender Differences in Depression. Current Directions in Psychological Science, 10, 173-176. https://doi.org/10.1111/1467-8721.00142

[25] Krantz, G., Berntsson, L. and Lundberg, U. (2005) Total Workload, Work Stress and Perceived Symptoms in Swedish Male and Female White-Collar Employees. European Journal of Public Health, 15, 209-214. https://doi.org/10.1093/eurpub/cki079

[26] Elias, H., Ping, W.S. and Abdullah, M.C. (2011) Stress and Academic Achievement among Undergraduate Students in Universiti Putra Malaysia. Procedia-Social and Behavioral Sciences, 29, 646-655. https://doi.org/10.1016/j.sbspro.2011.11.288

[27] Bamuhair, S.S., Al Farhan, A.I., Althubaiti, A., Agha, S. and Ibrahim, N.O. (2015) Sources of Stress and Coping Strategies among Undergraduate Medical Students Enrolled in a Problem-Based Learning Curriculum. Journal of Biomedical Education, 2015, Article ID: 575139. https://doi.org/10.1155/2015/575139 
Submit or recommend next manuscript to OALib Journal and we will provide best service for you:

- Publication frequency: Monthly

- 9 subject areas of science, technology and medicine

- Fair and rigorous peer-review system

- Fast publication process

- Article promotion in various social networking sites (LinkedIn, Facebook, Twitter, etc.)

- Maximum dissemination of your research work

Submit Your Paper Online: Click Here to Submit

Or Contact service@oalib.com 